\title{
Un silencio elocuente o la paradoja del final de Marcos."Y no dijeron nada a nadie porque tenían miedo" ( Mc 16, 8b) (I)
}

Xavier Alegre, Facultad de Teología de Cataluña, Barcelona, Centro de Reflexión Teológica, San Salvador.

No puede olvidarse que si la vida de Jesús hubiera terminado definitivamente en la cruz, nosotros estaríamos en la misma oscuridad que su muerte produjo entre sus discípulos. El que su vida no pudo terminar en la cruz, muestra, retroactivamente, la plenitud que esa vida encerraba y da base para que la comunidad creyente actualizara las posibilidades reales que esa vida tuvo (I. Ellacuría, "Por qué muere Jesús y por qué le matan", Diakonia 8, 1978, p. 75).

\section{Introducción}

Pascua se encuentra en el corazón mismo de la vida y de la teología cristiana. Se le podría denominar un artículo stantis et cadentis ecclesiae, pues, como dice san Pablo a los cristianos de Corinto, "si Cristo no resucitó, vana es nuestra predicación, vana también vuestra fe" (1Cor 15, 14). Por eso, el estudio de los textos que hablan directamente de los acontecimientos pascuales ha apasionado siempre a los especialistas en Biblia y a las comunidades cristianas. ¿Qué significan estos textos para nosotros? ¿Cómo se originó la fe pascual? ¿Cómo podemos experimentar ahora al resucitado en el corazón mismo de nuestras vidas? Estas preguntas son hoy más actuales que nunca, como lo demuestra la literatura abundante que se ha escrito últimamente sobre estos temas'.

1. Como muestra de ello puede verse la amplia bibliografía que recoge G. Ghiberti en E. Dhanis (ed.), Resurrexir (Roma, 1974) pp. 643-745, y que reúne la bibliografla 
La investigación bíblica más reciente sobre el modo como se originó la fe pascual de los primeros testimonios cristianos ha ido llegando, con razón, a la conclusión de que las apariciones del resucitado fueron como la espoleta, que provocó la explosión de la fe pascual, poco tiempo después de la muerte de Jesús". La iniciativa de Dios resucitando a Jesús, y "rompiendo las ataduras de la muerte, pues era imposible que ésta lo reluviera en su poder" (Hch 2, 24), fue revelada con una fuerza tan extraordinaria a los compañeros de Jesús, que transformó radicalmente sus vidas ${ }^{3}$. Del desencanto, la duda y el miedo 4 pasaron al entusiasmo, la fe y la valentía de proclamar un testimonio y un estilo de vida, que también a ellos les llevaría a la muerte, siguiendo a su Maestro (es lo

aparecida hasta el año 1973 inclusive. Para la bibliografía posterior, cfr., del mismo autor, La risurrezione di Gesì (Brescia, 1982), sobre todo las pp. 85-144. Sobre la fe en la resurtección de Jesús, desde distintas perspectivas, puede verse M. Fraijó, X. Alegre y A. Tomos, La fe cristiana en la resurrección. XXI Foro sobre el Hecho Religioso, Madrid, 1998.

2. Cfr. M. Hengel, "Ist der Osterglaube noch zu retlen?", Theologische Quartalschrift 153 (1973) 268. Esto lo reconoce hoy incluso R. Pesch que, a finales de los años 70, había sido el paladín, en el campo católico, de la tesis que sostiene que la fe pascual no se originó a partir de las apariciones del resucitado. Pesch propuso su tesis, en un artículo, que apareció en la revista Theologische Quartalschrift 153 (1973) 201-208 con el título: "Zur Entstehung des Glaubens an die Auferstehung Jesu. Ein vorschlag zur Diskussion". Este artículo provocó una discusión muy viva, entre los especialistas, de la cual dan testimonio las aportaciones de W. Kasper, M. Seckler, H. Schelkle, P. Siuhlmacher y M. Hengel, que fueron publicados en el mismo número de la revisıa, en que apareció el artículo de Pesch, cfr. Selecciones de Teología 15 (1976) 143-152. La postura de Pesch es analizada por A. Vögtle y completada por R. Pesch, en su obra conjunta: Wie kam es zum Osterglauben?, Düsseldorf, 1975. Un análisis a fondo de la tesis de Pesch puede encontrarse en la tesis doctoral de H. W. Winden, Wie kam es und wie kommt es zum Osterglauben?, Frankfurt, 1982, en la que encontraremos también una bibliografía abundante sobre el tema. De todos modos, Pesch, en una nueva toma de postura sobre el tema del origen de la le pascual, que apareció en francés con el título "La genèse de la foi en la résurrection de Jesús. Une nouvelle tentative" (en M. Benzerath, A. Schmid, J. Guillet (ed.), La Pâque du Criss. Mystère de salut, París, 1982, pp. 51-74), cambia su opinión y destaca, con razón, la importancia que las apariciones del resucitado tuvieron para el origen de la re pascual: "Las visiones pascuales son, en consecuencia, el lugar histórico, el presupuesto necesario del origen de la fe en la resurrección de Jesús después del Viemes santo" (p. 73).

3. Este aspecto nos recuerda el significado que las teofanías tienen en el Antiguo Testamento para personajes como Moisés, Isaias, etc. Sobre la peculiaridad de las teofanías del Antiguo Testamento, cfr. P. Seidensticker, Die Auferstehung Jesu in der Botschaft der Evangelisten, Suttgart, 1967, pp. 40ss.

4. Todos estos rasgos quedan recogidos en los textos que, en una segunda etapa de la uadición, desarrollaron narrativamente las apariciones del resucitado. 
que presuponen textos como Mc 10,39 y Jn 21, 18). Por esto podemos sacar la conclusión de que las apariciones del resucitado a sus discípulos son un elemento fundamental y constitutivo de los inicios de nuestra fe cristiana. Así lo entendieron los primeros cristianos, que dieron testimonio de la fe pascual, en uno de los credos cristianos más antiguos, un credo que Pablo nos ha transmitido, en su primera carta a los Corintios (1Cor 15, 1-5):

Porque yo les transmití, en primer lugar, lo que a mi vez recibí: que Cristo murí por nuestros pecados, según las Escrituras, y que fue sepultado. $Y$ que resucitó al tercer día, según las Escrituras, y que se apareció a Cefas y luego a los Doces.

Parece, pues, que podíamos esperar que en el evangelio más antiguo - me refiero al de $\mathbf{M c}^{6}$ - las apariciones del resucitado desempeñarían un papel fundamental. $Y$ que estas apariciones serían narradas con la amplitud que merecía un acontecimiento tan importante. Pero, de hecho, no es así, si se tiene en cuenta que los vv. 9-20 del último capítulo de Mc, con los que ahora concluye dicho evangelio, no fueron escritos por el redactor de Mc, sino que fueron añadidos posteriormente, en el siglo II?

5. Pablo subraya (cfr. los vv. 1-3) que ha recibido este texto de la tradición (probablemente hacia los años 35 ó 40 de nuestra era). $Y$ en los vv. 6.7 y $8 \mathrm{ss}$, recalca también la importancia y el significado de las apariciones del resucitado. Sobre la antigüedad y el significado de este credo y, más concretamente, de la fórmula griega "ôphthê" + dativo, que se encuentra en el v. 5, puede verse X. LéonDufour, Resurrección de Jesús y mensaje pascual, Salamanca. 1973. pp. 42-65 y 87-90; Winden op. cir., pp. 56-86 (con la bibliografía que cita); U. Wilckens, La resurrección de Jesús, Salamanca, 1981, pp. 19-30; S. Vidal, La resurrección de Jesús en las cartas de Pablo, Salamanca. 1982, pp. 155-185.

6. Personalmente, creo que la hipótesis que sostiene que el evangelio de $\mathrm{Mc}$ es el evangelio más antiguo ( $\mathrm{y}$ el que está en la base de los evangelios de Mt y de Lc) es la que mejor explica las semejanzas y las diferencias, que encontramos en los tres evangelios, denominados sinópticos. Sobre las ventajas y las dificultades que comporta la teoría denominada de "las dos fuentes", cfr. G. Strecker y U. Schnelle. Einfiihrung in die neutestamentliche Exegese, Göttingen, 1983, pp. 44-61. Ente los numerosos autores que sostienen también que $\mathrm{Mc}$ es el evangelio más antiguo, se puede ver, por ejemplo, J. Gnilka, El evangelio según san Marcos, Salamanca, 1986, Vol, I, p. 22 y P. Achtemeier, Mark, Philadelphia, 1975, p. 7.

7. Como es sabido, Mc 16, 9-20 es un texto, sin duda, canónico. Pero estos versos no son originales del que redactó el evangelio, como hoy reconocen de modo general los especialistas (cfr. por ejemplo, la nota que la Biblia de Jerusalén, Bilbao, 1967. p. 1.366, pone a estos versos). Los estudios de K. Aland, "Der wiedergefundene Markusschluss? Eine methodologische Bemerkung zur texlkritischen Arbeit", Zeitschrift für Theologie und Kirche 67 (1970) 3-13 y "Der Schluss des Markusevangeliums", en M. Sabbe (ed.). L'évangile selon Marc. Tradition et rédaction, Gembloux/Leuven, 1974, pp. 435-470, así como la tesis doctoral de J. 


\subsection{La sorpresa del final más antiguo de Marcos}

¿No resulta, entonces, sorprendente que el autor del primero de los evangelios no nos relate ninguna de las apariciones de Jesús resucitado? De hecho, ninguno de los que escribieron luego los otros evangelios canónicos aceptó concluir su obra con un final como el de Mc. Todos cuentan, con mayor o menor amplitud, las apariciones del resucitado (cfr. Mt 28, 9-10.16-20; Lc 24, 13-53; Jn 20, $11-21,23$ ). Y pocas décadas después de la redacción de Mc, muchas comunidades, al comparar su final con el de los otros evangelios, se apresuraron a "completar" su obra. Lo hicieron fundamentalmente con un resumen de los datos que habían encontrado en los otros evangelios y que ahora leemos en Mc 16, 9-20.

Por otro lado, no tiene por qué sorprendernos que Mt y Lc, que conocían el texto de Mc, completaran, independientemente el uno del otro', el texto del primero de los evangelios con relatos de apariciones pascuales. Pues el hecho de modificar el texto de Mc o de añadirle textos es un procedimiento bastante habitual en ellos. Lo encontramos en sus obras, cuando las tradiciones de las que disponen o las preocupaciones que guían la redacción de sus obras los llevan a hacer estas modificaciones o añadidos. Esto ocurre sobre todo cuando sus preocupaciones no coinciden con las de Mc y, por esto, se les escapa -0 no valoran- algunos de los acentos teológicos fundamentales que Mc dio a su obra. Así ocurre, por ejemplo, con el denominado "secreto mesiánico", en Mc.

Además, el final original de Mc resulta, de entrada, tan sorprendente, que, por sí mismo, parece invitar a la prolongación de la obra. Llama la atención que, una vez $\mathrm{Mc}$ ha relatado que las mujeres reciben la orden del mensajero divino de ir a los discípulos y recordarles las palabras de Jesús —en la última cena- de que después de su muerte fueran a Galilea, porque allí lo verán ( $c f r$. 16,7 ), el evangelio concluya con las palabras: "Y no dijeron nada a nadie, porque tenían miedo" (16, 8b).

¿Es posible que Mc acabara asł su obra? Pero si fue así, ¿qué nos podía querer decir, entonces, con un final tan sorprendente?

Hug, La finale de l'évangile de Marc. Mc 16,98-20, Parfs, 1978, resultan convincentes en este punto. En cambio, según A. Benilo, estos versos serían originales: véase su argumentación en "Marcos 16. Redacción y hermenéutica", Salmanticensis 24 (1977) 297-305.

8. Cfr. Aland, Der Schluss, pp. 454s; Gnilka, op. cit., Vol. II (1979), pp. 352-354. Hug, en cambio, cree que, al menos en parte, estos versos no dependen directamente de ninguno de los otros evangelios (efr. sus argumentos, op. cit., pp. 163-173).

9. Cfr. B. de Solages, Cristo ha resucilado. La resurrección según el Nuevo Testamento, Barcelona, 1979, pp. 136s. 
De entrada ya podemos sospechar que, como pasa a menudo en muchos textos bfblicos, este texto no se debe entender literalmente ${ }^{10}$, pues suponer que lo que el evangelista nos quiere comunicar es que las mujeres callaron realmente, nos crearía una serie de dificultades difíciles de solucionar. Si no se lo dijeron a nadie, ¿cómo se enteró Mc? Y si el silencio sólo fue provisional, ¿cómo es que no nos lo indica, como ocurre en el texto, añadido redaccionalmente", de Mc 9, 9, donde leemos: "les mandó que no explicaran a nadie lo que habían visto, hasta que el Hijo del hombre hubiese resucitado de entre los muertos"? ¿Cuál es, pues, para el autor el sentido de este texto enigmático?

\subsection{Mc concluyó conscientemente su evangelio en $\mathbf{1 6}, \mathbf{8 b}$}

La tesis que quiero desarrollar aquí es que este final desconcertante ha sido buscado conscientemente por Mc como colofón y clave de lectura de toda su obra. Para ello he de mostrar que no es absurdo que Mc acabara así su evangelio. Al contrario, si tenemos bien presente que el evangelio original de $\mathrm{Mc}$ concluía de esta manera, y llegamos a entender por qué concluía así, pienso que ello nos puede servir de llave maestra para profundizar en el pensamiento y en las preocupaciones teológicas del redactor del evangelio más antiguo. En este sentido, el silencio de la mujeres puede convertirse en un silencio muy elocuente y aleccionador.

Es, precisamente, este final sorprendente el que lleva a M. A. Tolbert a hablar de su poder retórico. Según ella,

la agonía de Jesús en Getsemaní, su coraje en el juicio y su desesperanza en la cruz han creado en la audiencia una profunda empatía hacia él, aumentando la firme identificación que ya existía con sus perspectivas, gracias al comentario fiable, realizado por el autor/narrador implícito a través de todo el evangelio. Además, el autor ha puesto en la picota, con ironía, tanto a los Doce como a los oponentes de Jesús, animando a la audiencia a buscar en otro lugar a aquellos que demostrarán fidelidad al ejemplo heroico de Jesús ante la injusticia notoria y el mal. Cuando las mujeres son introducidas, se convierten en el foco de estas esperanzas [...]. Aunque la tipología de la parábola del sembrador previene sobre todo del hecho de que la mayoría de los que oyen no dará fruto y los propios discipulos de Jesús han demostrado

10. De hecho, basta una comparación sinóplica de los cuatro relatos de los evangelios para poder descubrir que ninguno de los evangelistas pretendía una interpretación literalista e historicista de los detalles del relato, pues éstos son, a menudo. contradictorios (es muy iluminadora, en este sentido, la obra de H. Cousin, Los textos evangélicos de la pasión, Estella, 1981, que, en las pp. 81-135, trata de los relatos del sepulcro abierto).

11. Así Gnilka, op. cit., Vol. Il, p. 45. 
esta cruel verdad, resulta casi imposible creer que estas mujeres también fallarán, tanto porque ya han mostrado que son más fiables que los discípulos masculinos, como porque las expectativas y el deseo de la audiencia de que ellas tengan éxito son muy fuertes ${ }^{12}$.

$\mathrm{Y}$ añade ${ }^{13}$ : "Aristóteles argumentaba que la mejor trama para suscitar las emociones de la audiencia era aquella que presentaba un incidente inesperado que, a la vez, estaba en plena armonía con aquello que se ha hecho, ver Poética 1452a. El fallo de las mujeres es inesperado y, a la vez, previsible, supuesta la historia global del Evangelio".

El resto de mi artículo mostrará hasta qué punto esta autora tiene razón, al hacer esta observación.

Al mismo tiempo, pienso que la interpretación de este texto sorprendente nos ayudará a practicar uno de los principios fundamentales de toda exégesis: partir del texto mismo, leído en su contexto ("un texto, fuera de su contexto no es más que un pretexto").

Por otro lado, hemos de partir de un principio hermenéutico fundamental para toda interpretación de un texto bíblico. Si se quiere desentrañar el sentido de un texio, manipulándolo lo menos posible, nunca nos debemos colocar, de entrada, en el nivel del hecho histónico que se nos narra. No podemos presuponer que el autor nos quiera dar una especie de vídeo de las realidades o hechos a los cuales hace referencia, unos hechos que estarían vistos por un espectador más o menos objetivo, neutral. Más bien, nos debemos situar en el nivel del texto $^{14}$, a fin de poder dilucidar cuál es su forma o su género literario y, en consecuencia, cuál es el sentido que el autor que lo creó o que lo incorporó a su obra quiso darle. Esto es lo que nos recomienda la Constitución sobre la revelación divina del concilio Vaticano II $^{15}$. Sólo en un segundo momento, y en la medida en que el texto lo permita, nos podemos colocar al nivel de la historia, entendida ésta en sentido modemo, y preguntamos cuáles fueron los hechos que dieron soporte al texto en cuestión.

2. La vocación pascual de los discípulos de Jesús y el silencio interpelador de las mujeres (Mc 16, 7-8)

Si Mc 16,7-8 constituía el final original del evangelio y, además, estos versos son, como pienso, en buena parte obra de la redacción de Mc, que los ha

12. Sowing the Gospel. Mark's World in Literary-Historical Perspective, Minneapolis, 1989 , p. 296.

13. Ibid., n. 49.

14. Cfr. J. Delorme, El evangelio según San Marcos, Estella, 1978, pp. 24ss; cfr. también G. W. Ittel, Ostern und das leere Grab, Gütersloh, 1978, p. 17.

15. Cfr. Dei Verbum n ${ }^{\circ} 12$; cfr. tumbién G. Lohfink, Ahora entiendo la Biblia, Madrid, 1977. 
introducido en una tradición anterior sobre el sepulcro vacío, entonces, descubrir cuál es su significado para el autor puede ser muy aleccionador para nosotros.

Pero antes de explicar por qué este final no es casual en Mc y por qué está preñado de consecuencias para nuestra concepción actual del seguimiento de Jesús, hemos de considerar las razones que me llevan, con muchos especialistas en el tema, a la convicción de que Mc acabó conscientemente su obra con el texto de Mc16,8. Se trata, pues, de un punto importante para mi argumentación, que apunta a poner de relieve cuál es el corazón del pensamiento teológico de Mc.

\subsection{Marcos 16, 8: un final original}

Una lectura superficial, no suficientemente analítica, o que esté "dirigida"16 por una preconcepción determinada del texto de Mc, puede llevar fácilmente a pensar que no terminó $\longrightarrow$ por lo menos no quería terminar- su obra con el silencio de las mujeres del que habla 16, 8. De hecho, ya desde los mismos inicios de la difusión de Mc, este final sorprendió a muchos de sus lectores e intérpretes. Y ello fue así empezando por Mt y Lc, si, corno parece, éstos utilizaron el texto de Mc. De hecho, ya ellos tuvieron interés en cambiar este final.

Mateo modific6, en primer lugar, el silencio desconcertante de las mujeres, que se encuentra en Mc 16, 8. Así, en Mt 28, 8 leemos: "Ellas salieron a toda prisa del sepulcro y, con temor pero con mucha alegría, corrieron a llevar la noticia a los discípulos". Y, en segundo lugar, Mateo añadió también dos apariciones del resucitado, una a las mujeres que habian ido al sepulcro (cfr. 28, 9s) y otra a los Once discípulos, que habían ido a Galilea (cfr. 28, 16-20). Ello no tiene por qué sorprendernos, en principio, pues modificó también, a veces, las órdenes de silencio después de los milagros (compárese Mc 5, 43 con Mt 9, 26). Y suavizó el motivo de la incomprensión del Maestro por parte de sus discípulos (compárese Mc 4, 40 con Mt 8, 26).

También Lucas modificó el texto de Mc. En primer lugar, tampoco él deja que las mujeres callen: "Al volver del sepulcro, anunciaron todo esto a los once y a todos los demás" (Lc 24, 9; cfr. también 24, 22s) ${ }^{17}$. En segundo lugar, y debido al significado teológico que da él a la geografía' ${ }^{18}$, no deja salir a los discípulos de Jerusalén y de sus cercanías hasta pentecostés. $Y$, en tercer lugar, multiplica, por motivos teológicos y apologéticos ${ }^{19}$, las apariciones del resucita-

16. Llamo así a una lectura que se acerca al texto con un determinado prejuicio, que no le permite hablar por sí mismo.

17. Este último texto parece implicar que para Lucas, a diferencia de Mateo, Jesús no se apareció a las mujeres.

18. Cfr. H. Conzelmann, El centro del tiempo. La teología de Lucas, Madrid, 1974, p. 137; cfr. pp. 35-138.

19. Cfr. la obra de J. Kremer, Die Osterevangelien - Geschichsen um Geschichte, Stuttgart, 1977, donde este autor pone de manifiesto, a prop6sito de Mateo, Lucas 
do (a Pedro: 24, 34; a dos discípulos, en el camino de Emaús: 24, 13-35; a los Once y a sus compañeros: $24,36-49.50-52$ ) y las hace ganar claramente en "realismo" como contrapeso a las tendencias excesivamente espiritualizantes, es decir, despreciadoras de la resurrección corporal, que podían tener sus cristianos helenistas.

No sorprende, por tanto, y más si tenemos en cuenta que Juan acaba también su evangelio con unos amplios relatos de las apariciones del resucitado (cfr. Jn 20 y 21 ), que, ya muy pronto, las comunidades cristianas se preocuparan de "completar" la obra de Mc con unas apariciones del resucitado.

Esto supuesto, nos hemos de preguntar, entonces, si las comunidades completaron el texto de Mc en contra o no de la intención original de su autor. Las posibilidades son variadas. Por ejemplo, ¿no podrian haber cambiado el texto original, porque el final se había perdido o bien porque no les acababa de gustar el final que el autor le había puesto?

De entrada, conviene señalar que la crítica textual habla más bien en contra de la hipótesis de que Mc 16, 8 no fuera el final original de $\mathbf{M c}^{20}$. Pues, aparte de que es más fácil que se añadiera un texto que no que se suprimiera, nos encontramos, además, con que testimonios tan antiguos y fidedignos como los de los códices B y S, algunos padres de la Iglesia y varias traducciones antiguas atestiguan que el evangelio original llegaba sólo hasta 16,8. El análisis de las seis formas del final de Mc que se han encontrado hasta ahora vienen a confirmar este hecho. Por tanto, concluir que Mc no podía haber acabado asi su obra es una hipótesis que no podemos aceptar, a no ser que se aporten unos argumentos serios, que avalen esta afimación.

De hecho, sin embargo, el abanico de argumentos que se ha propuesto hasta ahora para dar apoyo a la tesis que sostiene que Mc no terminaba, inicialmente, en 16, 8, no resulta convincente. Fundamentalmente, podemos reducir a dos tipos los argumentos que se emplean: o bien, dicen unos, el final se perdió casualmente; o bien, dicen otros, fue suprimido a ciencia y conciencia.

\subsubsection{El final, ¿se perdió casualmente?}

La posibilidad no se puede excluir. Pero para poder aceptarla como probable hay que explicar cómo fue posible. Y aquí es donde empiezan los quebraderos de cabeza de los que proponen que el final se perdió. Pues para que ello fuera posible, se deberían haber acumulado toda una serie de casuali-

y Juan, el influjo de la apologética y de la teología en el desarrollo de las tradiciones pascuales; cfr. tambiên $\mathrm{H}$. Grass, Ostergeschehen und Osterberichte, Gottingen, "1962.

20. Cfr. Aland, Der Schluss. También Hug, op. cit., p. 212; cfr. pp. 187-215, llega a la conclusión de que el final original y definitivo de Mc se eneuentra en 16, 8. 
dades. Mencionemos algunas: 1) que la última hoja que no se perdió acabara exactamente con el final de la perícopa de la tumba vacía, cosa nada fácil, en un tiempo en el que los escritores escribían en letras mayúsculas y con una letra pegada a la otra; 2) que se perdiera el escrito original sin que se hubiera tenido tiempo aún de hacer ninguna copia de él; 3) que el autor y sus discípulos no lo hubieran podido completar ${ }^{21}$; 4) que pudiéramos explicar por qué en este evangelio, a diferencia de lo que ocurre en los otros, encontremos ahora hasta seis finales distintos de la obra. Si tenemos en cuenta todo esto, ¿parece verosímil que coincidieran tantas casualidades?

Por otro lado, suponer que Mc interrumpió su obra exactamente en este punto, por enfermedad, persecución o muerte, o porque quería escribir una segunda obra, o porque se le terminó el papel o la tinta (;todo se ha pensado!), tampoco resulta convincente, como subraya K. Aland ${ }^{22}$.

\subsubsection{El final, ifue suprimido conscientemente?}

Pero, ¿cómo explicar entonces este hecho? ¿Cómo explicar que no quedara ninguna copia más del original y que el autor no protestara ante el cambio? Y ¿qué razones se podían tener para hacerlo ${ }^{23}$ ?

Suponer que este final no era "ortodoxo", aparte de ser un anacronismo, resulta impensable en un hombre inspirado por Dios, que fue capaz de escribir una obra teológicamente tan profunda como la que encontramos en Mc 1, 1 16, 8. Tan profunda que las comunidades se apresuraron a difundir e "imitar", completando su obra.

Suponer que sus relatos de apariciones no encajaban bien con los de los otros evangelios, aparte de que implicaría que Mateo y Lucas Ias hubieran conocido - cosa que no parece que sea verdad ${ }^{24}$ - tiene en su contra, al margen de las dificultades mencionadas ya antes, el hecho de que los relatos

21. Cfr. Aland, Der Schluss, pp. 456s.

22. Ibid., p. 461. Según E. Trocmé, La formation de l'évangile selon Marc, París, 1963, p. 52, "la mulilación accidental del arquetipo o la crisis cardíaca que habría alcanzado al autor con la pluma en la mano, serfan unas suposiciones novelescas de un género ingenuo".

23. Cfr. la crítica que hace Aland de esta suposición, en Der Schluss, pp. 457-460. También E. L. Bode, The First Easter Morning. The Gospel Accounts of the Women's Visit to the Tomb of Jesus, Roma, 1970, llega a la conclusion, después de haber presentado las distintas conjeturas que se han hecho sobre la manera como "debía" haber continuado el relato de Mc (cfr. pp. 44-46) y de discutir los argumenlos en favor de la hipótesis de una continuación del evangelio original (cfr. pp. 46s), de que no hay ningún argumento que resulte convincente en favor de la hipótesis de una continuación del texto original de Mc, después de 16, 8 (cfr. p. 47).

24 Cfr. Solages, op. cis., p. 137. 
pascuales de Mateo y de Lucas tampoco encajan demasiado bien, entre ellos. Por lo menos en una visión superficial y espontánea de los mismos. Sin embargo, a pesar de esta dificultad, las comunidades no se preocuparon en absoluto de modificarlos, cuando tuvieron ocasión de verlos unidos. Luego tampoco tenían por qué suprimir los relatos originales de Mc.

\subsubsection{El v. 8b, ¿resulta un final imposible desde el punto de vista literario?}

Nos queda una última dificultad, que nos podráa obligar a postular un final distinto de Mc, si no somos capaces de solucionarla. Me refiero al hecho de que, según algunos autores $-y$ la objeción me parece, de entrada, seria-, en el tiempo en el que Mc escribió su obra era imposible que una perícopa - iy mucho menos una obra! - acabara con las palabras: "porque tenían miedo" (ephoboûnto gár) ${ }^{25}$.

Pero el análisis del texto de Mc y un mejor conocimiento de la literatura de la época ha quitado el apoyo a esta tesis. En efecto, el análisis literario revela la cantidad bastante notable de comentarios narrativos que en Mc son introducidos con la partícula griega gár (cfr. $1,16.22 ; 2,15 ; 3,21 ; 5,8.28 .42 ; 6$, $17.18 .20 .31 .48 ; 9,6.34 ; 10,22 ; 11,13 ; 14,2.40 .56 ; 15,10 ; 16,4.8$ ). Como subrayan T. E. Boomershine y G. L. Bartholomew ${ }^{26}$, estos comentarios son utilizados casi siempre para explicar cosas que se prestan a confusión o que resultan sorprendentes y que han sido narradas en la frase que las precede. En dos ocasiones ( $c f r .6,52$ y 14,2), estos comentarios con gár se encuentran también al final de una perícopa. Y, a la vez que responden a las cuestiones que provocan los textos que les preceden, plantean nuevas cuestiones.

Por otro lado, tampoco resulta impensable que Mc concluya un episodio e incluso todo un libro - constatando el miedo de las mujeres, pues parece ser una técnica narrativa que a él le gusta emplear: a menudo acaba un relato con una manifestación de los sentimientos internos de los personajes, que han sido testigos de una teofanía (cfr. también 6,51 s) o de una cristofanía.

Al mismo tiempo, se han encontrado textos antiguos, como el tratado 32 de Plotino, que literariamente acaban de un modo semejante ${ }^{27}$.

25. Cfr. W.L. Knox, "The Ending of St. Mark's Gospel", Harvard Theological Review 35 (1942) 33s (cfr. los argumentos que da en las pp. 13-23); cfr. también V. Taylor, Evangelio según San Marcos, Madrid, 1980, p. 738; Seidensticker, op. cir., p. 85; Aland, Der Schluss, pp. 461s. (en Aland se pueden encontrar otros autores, que defienden también esta tesis).

26. Sigo a estos autores, en todo este apartado, $c f r$. "The Narrative Technique of Mark 16, 8", Journal of Biblical Literature 100 (1981) 213-223.

27. Kreitton gàr to poioùn toù poiouménou; teleibteron gár (V. 5,13,36s, Herder, Vol. III a, p. 102), citado por P. W. van der Horst, "Can a Book end with gar? A Note on Mark 16,8", Journal of Theological Studies 23 (1972) 12; cfr. también O. 
Por todas estas razones, podemos concluir que 16,8 era el final original de $\mathrm{Mc}^{24}$. Si esto es así, no puedo sino subrayar la observación que hace $\mathrm{K}$. Aland: " $¿$ es, en verdad, pedir demasiado a los exegetas que saquen las consecuencias de este hecho?"29.

\subsection{La revelación pascual y la reacción de los hombres y de las mujeres}

\subsubsection{La paradoja del hecho cristiano}

La tesis que quiero desarrollar en este artículo es que el silencio de las mujeres en Mc 16, 8, en contraste con la orden que acaba de darles el ángel de ir a los discípulos para recordarles el encargo que Jesús les había dado a ellos de ir a Galilea ( $c f r .16,7$ con 14, 28), es un recurso literario de Mc para expresar una idea teológica fundamental. Mc emplea aquif este recurso muy conscientemente para poder concluir su obra de modo que quede bien claro en qué consiste la paradoja de la revelación cristiana, que se hizo plena realidad humana en Jesús de Nazaret. Con ello, además, Mc quiere recordar a su comunidad cuál es la piedra de toque - siempre escandalosa- de toda vida cristiana auténtica: el seguimiento de Jesús de Nazaret, el crucificado.

Creo que en el contexto de Mc 16, el v. 7 ("ahora vayan a decir a sus discípulos y a Pedro: él va delante de ustedes a Galilea; allí lo verán, tal como les dijo") alude a las apariciones del resucitado que Mc conocía, sin duda muy bien, pues forman parte del núcleo del kerigma primitivo (cfr. 1Cor 15, 5). En este supuesto, al dejar abierto el final de su evangelio y al no explicar ninguna aparición del resucitado, el redactor, además de dar un final al texto, que esté en consonancia con el resto de la obra, actualiza de manera significativa para su comunidad lo que fueron las experiencias pascuales de los primeros testigos de las apariciones del resucitado ${ }^{30}$. La sobriedad con que se alude al hecho es

Lindion, "Der vermisste Markusschluss", Theologische Bläfter 8 (1929) 229-234 y Aland, Der Schluss, pp. 462-464, el cual cita también el tratado 12 de Musonius Rufus, que concluye con las palabras gnôrimon gár.

28. Esta es también la conclusión que saca P. Hoffmann, Art. "Auferstehung Jesu Christi", Theologische Realenzyklopedie 4, p. 497. Lo mismo piensa W. Schmithals, Das Evangelium nach Markus, Gütersloh y Würzburg, ${ }^{2} 1984$, Vol. II, pp. 715-717, aunque él supone, a mi juicio sin razones convincentes, que el final actual $(16,9-20)$ reflejaría lo que era inicialmente el núcleo fundamental del evangelio que el redactor encontró y que él suprimió. Luego la Iglesia volvió a añadir este fragmento al evangelio.

29. Der Schluss, p. 469. Ya J. Wellhausen, Das Evangelium Marci, Berlín, 1909, p. 137, había notado, con razón, a propósito del final 16,8: "No falta nada; sería una lástima, que detuás viniera todavla alguna cosa".

30. La perícopa de Emaús ( $c f r$. Lc 24, 13-35) es también un modelo de actualización del mensaje pascual para la segunda generación cristiana: cfr. C. Perrot, "Emmaüs 
típica de los estratos más antiguos de la tradición de las apariciones, que no desarrollan narrativamente el acontecimiento, ni se detienen en explicar en qué consistió exactamente la aparición pascual. De hecho, la protofanía fundamental, la de Pedro, no es desarrollada ni tan siquiera en los estratos posteriores de la tradición canónica: sólo se alude a ella, por ejemplo, en Lucas 24, 34. Más bien, lo que aparece es que la realidad de las apariciones pascuales es constatada con fórmulas técnicas, que eran conocidas gracias a las teofanías que se encuentran en el Antiguo Testamento y que subrayan la iniciativa de Dios, que lo revela a sus testigos escogidos (cfr. 1Cor 15, 5-6.7.8-11) ${ }^{31}$.

En la misma línea, Pablo, el único autor que nos da un testimonio directo y personal de una aparición pascual, insiste también en los elementos de conversión y de misión que comportaba la aparición del resucitado, elementos que se encuentran implícitos en las fómulas más antiguas ${ }^{32}$.

En este sentido, Mc está muy cerca de la tradición más antigua, pues tampoco él relata las apariciones, sino que más bien subraya su carácter de conversión y de vocación ${ }^{33}$. Propio de él -y ésta será su gran aportación teológicaes haber intuido que la mejor manera de explicar a la comunidad el significado de la fe pascual es narrar la vida de Jesús de Nazaret como vocación a su seguimiento y como correctivo de un entusiasmo pascual demasiado exaltado ${ }^{34}$. Pues, a diferencia de determinadas experiencias religiosas - los evangelios apócrifos son una muestra de la facilidad con que se pueden manipular estas experiencias-, la vida de Jesús no es manipulable, sino que ha de ser interpretada dentro de unas coordenadas bien concretas, que vienen configuradas esencialmente por la cruz.

ou la rencontre du Seigneur" (Lc 24,13-35), en Benzerath, etc. op. cit., pp. 159166, sobre todo pp. 165s.

31. Cfr. J. Delorme, "La resurrección de Jesús en el lenguaje del Nuevo Testamento", en H. Cazelles, J. Delorme, L. Derousseaux, J. le Du, R. Mace, El lenguaje de la fe en la Escritura y en el mundo actual, Salamanca, 1973, pp. 140-144.

32. Cfr. Léon-Dufour, op. cit., pp. 93-109. Resulta interesante comparar el testimonio personal que da Pablo de su aparición del resucitado con el desarrollo narrativo posterior que nos ofrece Lucas en Hechos 9, 1-19; 22, 6-21 y 26, 12-23 (cfr. LéonDufour, op. cit., pp. 115-133).

33. El elemento de la conversión lo acentúa E. Schillebeeckx, Auferstehung Jesu als Grund der Erlösung, Freiburg, 1971, pp. 91ss; y también en su obra Jesús. La historia de un viviente, Madrid, 1981, pp. 351-355. La mision es remarcada por Léon-Dufour, op. cit., pp. 96ss.129.139ss.152ss.

34. Las corrientes entusiastas dentro de las primeras comunidades cristianas crearon serios problemas al cristianismo primitivo, como puede verse, por ejemplo, en la segunda carta a los Corintios. E. Käsemann muestra muy bien este aspecto en su interesante libro La llamada de la libertad, Salamanca, 1974. 
Por esto podemos concluir que su añadido redaccional, al final del evangelio $(16,8 b)^{35}$, quiere recordar al lector o al oyente que la perspectiva desde la que ha explicado la vida de Jesús — la de la cruz — sigue siendo válida, incluso después de pascua.

En orden a justificar lo que acabo de decir, consideraré, primero, la tradición de la tumba vacía, que constituye la última perícopa original de Mc, a fin de poder situar, después, en su contexto inmediato, los retoques redaccionales de los vv. 7 y 8 b y explicitar su significado.

\subsubsection{La tradición de la tumba abierta y vacía}

Es difícil determinar con exactitud el alcance de la tradición que Mc recoge en 16, 1-8. Los especialistas no acaban de ponerse plenamente de acuerdo en este punto ${ }^{36}$. Pero para el tema que nos interesa, no es necesario clarificar este punto en todas y cada una de las palabras de la perícopa. Basta con que podamos constatar que el núcleo teológico fundamental lo constituían la mayor parte de los vv. 5.6.8a, que contienen el mensaje pascual de la comunidad cristiana primitiva. Este mensaje está enrnarcado por la entrada y la salida de las mujeres del sepulcro. Y por su reacción, que es típica de una angelofanía ${ }^{37}$ :

Cuando [las mujeres] entraron en el sepulcro, vieron a un joven sentado a la derecha, que iba vestido con una túnica blanca. Ellas se asustaron. Pero él les dijo: No se asusten. Buscan a Jesús de Nazaret, el crucificado. Ha resucitado. No está aquí. Miren el lugar donde lo pusieron. [...] Ellas salieron huyendo del sepulcro, llenas de temor y asombro.

35. Creo, con la mayoria de los autores (cfr. Gnilka, op. cil.. Vol. II, p. 338 y los autores citados por él), que el v. 8 b es redaccional. En cambio, Pesch, Markus, II, pp. 519-521, cree que es tradicional. Pero no convence.

36. Lo muestra claramente una simple ojeada al artículo de F. Neirynck, "Marc 16, 18. Tradition et rédaction", Ephemerides Theologicae Lovaniensis 56 (1980) 56-88, que recoge los distintos intentos de los especialistas sobre este problema. Parece claro, sin embargo, y así lo ven la absoluta mayoría de autores, que Mc utiliza aquí una tradición ( $c f r$. por ejemplo, B. van Iersel, "La resurrección de Jesús, iinformación o interpretación?", Concilium 60 (1970) 59, cfr. pp. 57-62). No parecen convincentes las razones que da J. D. Crossan, "Empty Tomb and Absent Lord (Mark 16, 1-8)", en W. H. Kelber (ed.). The Passion in Mark, Philadelphia, 1976, pp. 135-152, para defender que toda la pericopa es redaccional. Sobre los elementos redaccionales y uadicionales de los vv. 1-4, cfr. Gnilka, op. cit., Vol. II, pp. 337340 (y los autores citados por él); Kremer, Diskussion, pp. 146-153 y Osterevangelien, pp. 45-49; J. Schmitt, "Résurrection de Jésus dans le kerygme, la tradition, la catéchèse", Dictionnaire de la Bible Supplément, X, p. 757s. La tradición empezaría diciendo que María Magdalena (y quizás otras mujeres) irian al sepulcro. 
En el corazón de la perícopa tradicional se encuentra, por tanto, en primer lugar, la confesión "Jesús de Nazaret" ${ }^{38}$, el crucificado, ha resucitado". El marco narrativo que lo rodea —el joven sentado a la derecha, el "no tengan miedo" y la reacción de espanto por parte de las mujeres - revela que la comunidad cristiana ha llegado a esta confesión no por medio de la lógica humana, sino por revelación divina ${ }^{39}$.

En segundo, lugar se indica - no como una prueba de la resurrección ${ }^{40}$, sino como confurmación o signo típico de los relatos de asunción al cielo- que la búsqueda del cuerpo del personaje es inútil, pues no se encuentra en la tumba ${ }^{41}$.

37. Hoffmann, op. cil., p. 498.

38. Las palabras "de Nazaret" (iòn Nazarênón) podrian ser redaccionales (cfr. J. Kahmann, “'Il est ressuscité'. le crucilié'. Marc 16, 6a et sa place dans l'évangile de Marc", en Benzerath, etc., p. 123; Hoffmann, op. cit., p. 498), pues esta formulación es típica de Mc ( $c f r .1,9.24 ; 10,47 ; 14,67$ ), como nota Bode, op. cit., pp. $28 \mathrm{~s}$ (pero él cree que Mc sólo ha cambiado Nazóraíon por Nazarênón). L. Schenke, Auferstehungsverkündigung und leeres Grab. Eine traditonsgeschichtliche Untersuchung von Mk /6, I-8, Stuttgart, ${ }^{2} 1969$, pp. 75s., no acaba de ver con claridad si la palabra es de la tradición o bien de la redacción. En todo caso, como indica F. Zehrer, Die Auferstehung Jesu nach den vier Evangelien, Viena, 1980, p. 33: “Como 'el Nazareno', Jesús era despreciado entre los judíos (cfr. Jn 1, 46), como 'el Crucificado' era considerado, de acuerdo con Di 21, 23 ('maldito el que cuelga de un madero', citado por Gal 3, 13) como un maldiro. Con ello la afirmación teológica de estas dos denominaciones es la siguiente: Este Jesús, que se convirtió para los judlos en un gran 'escándalo' (cfr. 1Cor 1, 23: [...]), ha sido resucitado por Dios" (los subrayados son suyos). Si la palabra fuera de la redacción, esto no haría sino confirmar el interés del redactor por la vida de Jesús, que aquí aparecería íntimamente relacionada con la proclamación de la resurrección. Es importante remarcar que la palabra 'crucificado" (estaurôménon) se encuentra aqul en el tiempo griego denominado "perfecto": la crucifixión no es vista tan sólo como un acontecimiento del pasado (se emplearía, entonces, el aoristo), sino como algo que sigue teniendo vigencia ahora ( $c f r$. C. Wiener, "Le mystère pascale dans le deuxième évangile. Recherches sur la construction de Marc 14-16", en Benzerath, etc., op. cil., p. 143). La palabra egérthê es una cita del kerigma cristiano primitivo, que encontramos en 1 Cor 15 , 4 (cfr. R. Pesch, Das Markusevangelium, Freiburg, Vol. II, 1977, p. 533).

39. Gnilka, op. cil., Vol. II, p. 401; cfr. tambiên Delorme, La resurrección, pp. 148s; Kremer, Zur Diskussion, p. 139.

40. Cfr. W. Nauck, "Die Bedeutung des leeren Grabes lür den Glauben an den Auferstandenen", Zeitschrifi für die Neutestamentliche Wissenschaft 47 (1956) 251s; Delorme, La resurrección, Pp. 148s; Kremer Diskussion, p. 139; G. Kittel, "Das leere Grab als Zeichen für das uberwundene Totenreich", Zeitschrifi für Theologie und Kirche 96 (1999) 461, y los autores citados por ella, ibid., n. 14.

41. Así to ha explicado bien Pesch, Markus, Vol. II, pp. 522-527 y 352s; cfr. Lambién su artículo "El 'sepulcro vacío' y la fe en la resurrección de Jesús", Revista Carbli- 
Mc, por tanto. concluye su obra con una perícopa que subraya el triunfo del resucilado, vencedor de la muerte ${ }^{42}$. Si tenemos en cuenta el significado fundamental que la resurrección tuvo en el kerigma primitivo - si bien muy pronto fue considerada en relación con la cruz, como es el caso en el texto actual de Mc (cfr. 1Cor 15, 3-5; Mc 16,6) - y en los otros evangelios, parece que la resurrección debería ser la piedra angular o el clímax que configurara todo el evangelio de Mc. Pero los retoques redaccionales de los versos 7 y $8 \mathrm{~b}$ muestran que no es ésta la intención del redactor del más antiguo de los evangelios. El análisis de estos dos versos nos revelará dónde quiere situar Mc el clímax de su obra y cuáles son los motivos que lo llevaron a hacerlo así.

\subsubsection{El encuentro con el resucitado, en Galilea (v. 7)}

El primer añadido redaccional importante ${ }^{43}$ lo sitúa Mc inmediatamente después del kerigma pascual. Lo presenta como un encargo que el ángel da a las mujeres para que lo comuniquen a los discípulos: "Ahora vayan a decir a sus discípulos y a Pedro: El va delante de ustedes a Galilea; allí lo verán, tal como les dijo" (v. 7). ¿Cómo hay que entender este verso? ¿Qué pretende Mc con él?

Algunos autores han creído que con este verso Mc hacía referencia a la visión del Hijo del hombre en la parusía ${ }^{44}$. Pero cuando escribe el evangelio, tanto él como su comunidad saben bien que ni Pedro, ni los discípulos fueron

ca Internacional 4 (1982) 724-740 (condensado en Selecciones de Teología, 22 (1983) 101-108) y Hoffmann, op. cir., p. 499 (sobre el significado de la tumba vacla en la investigación actual, cfr. mi noticia complementaria sobre este tema, en Selecciones de Teología, op. cit., pp. 108-110).

42. Este es el significado fundamental de la perícopa de la tumba vacía, o mejor, "abierta", como indica Léon-Dufour, op. cit., pp. 168-170.175.181-185 (este aspecto aparece aún más claramente en el relato de Mi).

43. Cfr. Bode, op. cir., pp. 35-37; Kremer, Osterevangelien. p. 46; Gnilka, op. cil., Vol. II, p. 402; W. Grundmann, Das Evangelium nach Markus, Berlín, ${ }^{3} 1965$, p. 321. Con razón nota Gnilka, op. cit., Vol. II, pp. 295.395-397 y 402, que ya 14, 28 es un texto propio de la redacción (e indica los autores que opinan lo mismo). Pesch, Markus, Vol. I, p. 13, y Vol. II, p. 382, cree, en cambio -pienso que sin razones convincentes- que 16,7 y 14, 28 se encontraban ya en la tradición que Mc recibió. También, según D. Dormeyer, Die Passion Jesu als Verhaltensmodell. Traditions- und Redaktionsgeschichte der Markuspassion, Mlinster, 1974, pp. 226229 , el v. 7 (como el v. 8b) sería de la tradición, porque formaría parte del esquema clásico de las angelofanías.

44. Así, E. Lohmeyer, Galilea und Jerusalem, Göttingen, 1936, pp. 10-14, y Das Evangelium nach Markus, Göttingen, ${ }^{12} 1953$, p. 356. Cfr. también W. Marxsen, El evangelista Marcos. Estudio sobre la historia de la redacción del Evangelio, Salamanca, 1981, pp. 77-85.104-109 (el trasfondo histórico que presupone es cuestionable); F. Belo, Lectura materialista del Evangelio de Marcos, Estella, 1975. pp. 359-361. 
testigos de la parusía de Jesús, en Galilea ${ }^{45}$. No será, pues, ésta la interpretación adecuada del texto.

La "visión" del v.7 se refiere, más bien, a las apariciones del resucitado que, históricamente, tuvieron lugar, según parece, al menos en sus inicios, en Galilea ${ }^{46}$. Pero a Mc, más que el detalle histórico, le interesa el significado de eslas apariciones. Situándolas dentro del relato de la tumba abierta y vacía, Mc consigue, por un lado, relacionar dos tradiciones pascuales, que se originaron con independencia la una de la otra, probablemente en lugares diferentes (Jerusalén y Galilea) ${ }^{47}$. Por otro lado, quiere indicar a su comunidad, por medio del dinamismo del relato, que no es en la tumba donde se encuentra Jesús, ni es por la tumba como se llega a la fe en el resucitado. Se le encuentra en "Galilea". Allí va Jesús delante de ellos. Allí lo encontrarán, si se fían de él y se dejan guiar por la palabra de Jesús de Nazaret, que él les dio durante su vida pública ( $c f r .14,28)$. Al mismo tiempo, Mc señala a su comunidad cómo ella puede experimentar, ahora, la presencia del resucitado.

Sin embargo, ¿por qué se limita a una alusión a estas apariciones y no las explica narrativamente, tal como lo hicieron luego el resto de los evangelistas?

No me parece una respuesta suficiente suponer, como hacen algunos autores $^{48}$, que, al ser el evangelio más antiguo, no conocía todavía el desartollo narrativo de las apariciones pascuales. De hecho, los otros evangelistas - por lo menos Lucas y Juan- no crearon totalmente sus narraciones pascuales, sino

45. Asl, tambiến lo ve A. Descamps, "La structure des récits évangeliques de la résurrection", Biblica 40 (1959) 736.

46. Cfr. H. Grass, Ostergeschehen und Osterberichte, Göttingen, ${ }^{2} 1962$, pp. 28 y 119; G. Lohlink, "Der Ablaur der Osterereignisse und die Anfänge der Urgemeinde", Theologische Quarlalschriff 160 (1980) 161-174 (condensado en Selecciones de Teología 21 (1982) 17-25 con el título "El desarrollo de los acontecimientos pascuales y los comienzos de la comunidad primitiva", cfr., p. 18).

47. Cfr. U. Wilckens, La resurrección de Jesús. Estudio hissórico-crítico del testimonio bíblico, Salamanca, 1981, p. 52. Por otro lado, me parece sufieientemente probado hoy que la tradición de la tumba vacía se originó en Jerusalén. En cambio no me parece convincente la tesis que propugna que el medio vital de esta tradición sea una leyenda cultual etiológica, relacionada con la veneración de la tumba de Jesús, en Jerusalén. Esta tesis la proponen, por ejemplo, Schenke, op. cit., sobre todo pp. 80,113, y J. Delorme, "Resurrección y sepulcro de Jesús: Marcos 16, 1-8 en la tradición evangélica", en P. de Surgy, P. Grelot, M. Carrez, A. George, J. Delorme, X. Léon-Dufour, La resurrección de Crisio y la exégesis moderna, Madrid, 1974, pp. I24-136, que se apoyan fundamentalmente en G. Schille, "Das Leiden des Herm. Die evangelische Passionstradition und ihr 'Sitz im Leben'", Zeitschrift für Theologie und Kirche 52 (1955) 161-205 (cfr. también Nauck op. cit., pp. 260s): cfr. la crítica que les hace Kremer, Diskussion, pp. 149s.

48. Por ejemplo, K. Koch, Die Auferstehung Jesu Christi, Tübingen, 1959, p. 35. 
que se apoyaron en tradiciones anteriores. $Y$ textos como el de la transfiguración de Jesús (cfr. Mc 9, 2-9), podían servirle de pauta para este desarrollo narrativo. Además, al menos en el relato de la tumba vacía, el mensaje pascual ya había sido desarrollado de forma narrativa.

Personalmente, pienso que el motivo ha de ser más profundo. De hecho, un examen cuidadoso del texto nos manifestará que este hecho de no narrar las apariciones pascuales responde a las preocupaciones y a los acentos teologicos, que son propios de Mc.

En primer lugar, notemos que no es una casualidad que en Mc el encuentro con el resucitado esté situado en Galilea, pues Galilea tiene, de hecho, un significado peculiar, en su evangelio. Se trata de un significado que contrasta con la manera como Mc habla de Jerusalén ${ }^{\prime 9}$. Pues, mientras Jerusalén es vista de modo negativo como el lugar desde el cual vienen los enemigos de Jesús (cfr. 3,$22 ; 7,1)$ y en el cual Jesús padecí́ y murió (cfr. 10, 33; 14-15), Galilea, en cambio, es vista de una manera muy positiva.

Galilea es el lugar en el cual se inició la actividad pública de Jesús (cfr. 1, 14) y en el que realizó la mayor parte de su revelación con poder (cfr. 1,21 - 8, 26). Es en Galilea donde Jesús escogió a sus discípulos (cfr. 1, 16-20; 2, 14; 3, 13-19) y donde los envió a predicar (cfr. 6,6b-13). También alli preparó a sus discípulos para la crisis de la pasión ( $c f r .9,30$ ss). Y desde Galilea empezó la misión cristiana a los paganos ( $c f r .5,1-20 ; 7,24-30$ ).

Dada, pues, la importancia que tiene la vida de Jesús en Galilea (la muerte en la cruz, que tuvo lugar en Jerusalén, fue la consecuencia de la actividad de Jesús, en Galilea: $c f r .3,6.22-30 ; 7,1-15 ; 8,11 ; 8,31 ; 9,31 ; 10,32-34)$, Mc quiere subrayar que es en Galilea donde los discípulos reencontrarán al resucitado. Pues en Mc, Galilea, más que un lugar geográfico, es un lugar teológico: es un lugar que viene caracterizado por el seguimiento del estilo de vida de Jesús de Nazaret y en el cual la comunidad de Mc, a semejanza de los primeros discípulos, puede hacer ahora una experiencia cualificada del resucitado.

En segundo lugar, Mc muestra con el v.7 que para encontrar al resucitado -y él quiere insistir mucho en este aspecto- no es necesario volver a Jerusa-

49. La mayorfa de los textos que hablan de Galilea pertenecen al estrato redaccional del evangelio (cfr. Gnilka, op. cit., Vol. I, p. 81). Sobre el significado de Galilea en Mc, cfr. Pesch, Markus, Vol. I, p. 104; Gnilka, op. cil., Vol. I, pp. 80-81; E. Manicardi, Il cammino di Gesì nel Vangelo di Marco, Roma, 1981, pp. 190s., y la bibliograffa citada por ellos. Lohmeyer, en su obra Galilea und Jerusalem, sostuvo la tesis, aunque no resultó convincente, de que Galilea es el lugar en el que vive la comunidad de Mc. Se tratarla de una comunidad que estaba en oposición a la comunidad de Jerusalén (cfr. también Marxsen, op. cis., pp. 49-109, quien dedica todo un capítulo a estudiar el significado del marco geográfico de $\mathrm{Mc}$ ). 
lén. Tampoco es necesario ir a la tumba, que estaba vacía. $\mathrm{Ni}$ esperar unas experiencias extraordinarias, de tipo extático, que dieran seguridad a la comunidad — una comunidad, por cierto, que es perseguida, como se puede deducir de lo que se dice en Mc $13^{\text {st) }}$. No. La revelación de Dios resucitando a Jesús no apunta ahora a un pasado estático, fosilizado o manipulable por el creyente, sino que esta revelación está llena -y es algo que pertenece a su esencia- de un dinamismos! marcado radicalmente por la vida de Jesús de Nazaret. Por esto, el ángel encarga a las mujeres que digan a los discípulos que Jesús los "precede" hacia Galilea (pro-agein, como fue delante de ellos hacia Jerusalén para sufrir la pasion: $c f r .10,32)^{52}$.

Con este último rasgo, Mc pone de manifiesto que las primeras experiencias pascuales - y en esto es fiel a la tradición más antigua - fueron esencialmente "vocaciones"s3 para los que las vivieron. Se trata de vocaciones que no hacían referencia al seguimiento de un personaje mítico, sino que estaban configuradas radicalmente por la vida y por la palabra de un personaje histórico bien concreto, Jesús de Nazarel, a quien Dios resucitó de entre los muertos. Pues la resurrección significaba que Dios le había dado la razón contra sus adversarios. Y confirmaba, por tanto, que había vivido con plenitud, como Hijo, la fidelidad a la voluntad del Padre.

No es casual, entonces -insisto en este punto porque la estructura del evangelio es uno de los elementos más típicos de la labor redaccional de $\mathrm{Mc}^{54} \mathrm{y}$, por tanto, es una clave de lectura fundamental de su obra- que Mc, después del prólogo teológico del evangelio (1, 1-13), en el cual el Hijo es presentado con los rasgos del Siervo de Yahvé $(c f r .1,11)^{55}$, y del resumen programático de la predicación de Jesús (cfr. 1, 14s), empiece y acabe el evangelio de Jesús de Nazaret con la vocación de los discípulos (cfr. 1, 16-20 y 16,7). De este modo, dicha vocación

50. Cfr. G. Minette de Tillesse, Le secret messianique dans l'évangile de Marc, París, 1968, p. 435.

51. Como señala B. Standaert, L'évangile selon Marr. Commentaire, París, 1983, a propósito de I, 38-39 y de 16, 6-7: "Jesús reenvía a otro lugar; y el joven hace lo mismo: 'No está aquí; los precede a Galilea'. Este 'otro lugar' permanece a lo largo de todo el relato como una dinámica misionera, que es experimentada también por los cristianos de Mc" (p. 112; el subrayado es del autor).

52. Sobre el significado de pro-agein, que aparece también en 6,$45 ; 11,9$ y 14, 28, cfr. Manicardi, op. cil., pp. 173-175.

53. Por ejemplo, la aparición a Pablo (cfr. Léon-Dufour, op. cit., pp. 96ss. Como nota Manicardi, op. cit., pp. 178-182 (cfr. 191), el idontes del v. 7 (cfr. 4, 12; 15, 39; cfr. (ambién 8, 17-21) es un "ver", que implica que los discípulos retoman el seguimiento y dan el paso definitivo hacia la fe completa.

54. Cfr., infra, n. 110.

55. Cfr. J. Jeremias, Art. páis theoa ThW V 699; Pesch, Markus, Vol. II, pp. 92s; como señala Pesch (ibíd., p. 97), Mc subraya mucho el nexo entre la filiación 
forma una inclusión que enmarca toda la narración del evangelio. Mc quiere manifestar así que la manera como ahora se puede explicitar lo que fueron las primeras experiencias pascuales y la manera como toda persona se puede abrir a la comunicación, siempre gratuita, del resucitado, es narrando la vida y la obra de Jesús de Nazaret, haciendo caer en la cuenta de que dicha narración invila al seguimiento de Jesús, tal como lo hicieron ya los primeros discípulos.

Esta es, precisamente, una de las grandes aportaciones teológicas de Mc. Pues haber puesto de manifiesto que la vida concreta de Jesús de Nazaret una vida que le llevó a la muerte en cruz, por su apuesta decidida y absoluta por el bien del ser humano, sobre todo del que se encuentra en necesidad, como expresión máxima de la voluntad de Dios- es el punto de referencia decisivo e insustituible de lo que significa hoy ser cristiano: seguir a Jesús de Nazaret. Con gran sencillez, Mc ha sabido poner muy bien de manifiesto hasta qué punto la vida concreta de Jesús ha sido sumamente provocadora para según qué lipo de religiosidad a la cual molesta la opción preferencial por los pobres y las críticas que hace Jesús de las religiosidades "instaladas". Este aspecto continúa siendo hoy muy actual, como puede verse por las aportaciones de la teología de la liberación y por las reacciones que ésta provoca.

$\mathrm{Si} \mathrm{Mc}$ insiste en este seguimiento concreto, no manipulable, de la vida de Jesús de Nazaret, ello se debe al hecho de que cayó en la cuenta que la experiencia pascual no había comunicado a los discípulos cosas radicalmente nuevas, distintas de las que había enseñado Jesús, en su vida terrena. Más bien les abrí́ los ojos para comprender en profundidad, guiados por la revelación de Dios, quién era aquel personaje a quien ellos habían negado y abandonado ante la amenaza y la dureza de la cruz. Era realmente el Hijo de Dios. Y ahora, resucitado por Dios, podía hacerse realmente presente, de un modo nuevo, misterioso y gratuito, pero cierto, en medio de sus vidas. Esta experiencia les dio ahora fuerzas para seguir a Jesús, en el camino que lleva a la cruz. Pues para Mc, este seguimiento (cfr. 8,34$)$ es la conditio sine qua non de toda experiencia cristiana auténtica.

Por eso, Mc, más que distraer la atención de la comunidad con unos relatos de las apariciones pascuales, que podrían confirmar - como explicaré más adelante- determinadas tendencias más bien triunfalistas de la comunidad, prefiere remitir al lector, después de pascua, al relato de la vida de Jesús de Nazaret. Con ello pretende que la comunidad descubra cuáles son las coordenadas que

divina de Jesús y su pasión. Gnilka, op. cir., Vol. I, p. 58; cfr., pp. 61s, cree que en la perícopa el título de "Hijo" ha desalojado el título de "Siervo", que es el que se encontraráa en la tradición. En contra de una alusión al "Siervo", de ls 42 se pronuncia H. J. Steichele, Der leidende Sohn Gottes. Eine Untersuchung einiget alttestamentlicher Motive in der Christologie des Markusevangeliums. Regensburg. 1980, pp. 121-135.156s. 
sitúan siempre a toda experiencia cristiana, también después de pascua. Al mismo tiempo, Mc explica "pedagógicamente", la vida de Jesús, de modo que pueda servir de guía y de lección para su comunidad"s6.

\subsubsection{El Deus semper maior de la Biblia}

Con este dinamismo de vocación, que Mc considera inherente a las manifestaciones del resucitado, el autor del primero de los evangelios no hace algo radicalmente nuevo, sino que permanece fiel a un rasgo, que es típico de toda revelación bíblica.

Como han notado los especialistas, a propósito de la revelación del nombre de Dios, en el Antiguo Testamento ( $c f r$. Ex 3, 14), la palabra "Yahvé", más que comunicar un "nombre" en el sentido clásico que esta palabra tiene en el mundo judío (de dar a conocer la esencia de una persona o cosa), es un nombre que comporta en esencia un elemento dinámico, no manipulable por el creyente. En este sentido, apunta hacia el futuro del pueblo de Israel, que experimentará cómo Dios está con él, en su caminar hacia la tierra prometida y, luego, a lo largo de toda su vidas?

Para Mc, Jesús ahora, como Yahvé, en el Antiguo Testamento, es el que va delante de los discípulos, representantes de la comunidad cristiana, hacia la Galilea de la promesa, lugar privilegiado de la manifestación de la vida y de las palabras de Jesús. Y lugar en el cual se inició, prefigurando el futuro, la tarea misionera de la comunidad cristiana a favor de los paganos.

Este dinamismo evita, al mismo tiempo, que los títulos que ahora puedan darse a Jesús que, como Hijo resucitado, participa plenamente del poder y de la

56. B. Van lersel (Markuskommentar, Düsseldorf, 1993, p. 254) destaca el hecho de que el texto original de Mc, al no narrar las apariciones del resucitado, deja totalmente abierta la cuestión de si los disclpulos llegaron a ver al resucitado; o, en todo caso, cuándo y cómo lo vieron. Pero este final irritante no tiene por qué desorientar al lector, pues, entretanlo, si ha leído bien el evangelio, ya no está ciego, sino que se ha convertido en alguien que "ve". Está tan implicado en el relato que el mensaje de Jesús se ha convertido en un reto para él. Mc le ha ofrecido al lector algo más que un modelo de interpretación. Le ha ofrecido un modelo de acción para su propio camino de vida.

57. Cfr. la nota que la Biblia dels monjos de Montserrat, Andorra, ${ }^{2} 1975$, p. 2535, pone al texto de Ex 3, 14. A propósito de la dimensión histórica del nombre leemos allí: "Dios está con Moisés para ayudarle en la obra de salvación (cfr. v. 12; 4, 12-15). La frase enigmática equivaldría a 'Yo estoy con vosotros para salvaros'. La revelación del nombre va ligada a la revelación y a la gesta de liberación del pueblo (cfr. 16 ,6; 20, 2; Lv 11, 45; Di 5,6 ; SI 81, 11; Os 12, 10; Ez 20, 5s). [...] Es a través de la historia de salvación que Dios se irá manifestando tal como es y como actúa hasta el pleno cumplimiento en Jesús (Yahvé salva) por medio del cual viene la salvación". 
gloria de Dios, se conviertan en títulos "ya hechos", "estáticos" ( $\mathrm{el}$ nombre de Dios nunca es manipulable!). Esta gloria del resucitado aparecía ya prefigurada en la transfiguración ( $c f r .9,2 s s$ ). Pero ya allí, Mc ponía la sordina de la cruz como contrapeso de esta experiencia gloriosa (cfr. 9, 9). Y ello es así, porque Mc tiene muy clara conciencia de que los títulos que ahora se pueden aplicar a Jesús (los de Mesías, Hijo, etc.) pueden convertirse en una especie de biombo, que dificulte su verdadera comprensión, en una mampara teológica que no deje "ver" realmente quién es Jesús y cómo se hace presente hoy, en la comunidad. Pues, para Mc, estos títulos gloriosos se pueden convertir en ambiguos, si no quedan configurados por los rasgos que son propios del Dios vivo, que se ha revelado definitivamente en Jesús de Nazaret, el crucificado. De este modo, así como Israel sólo fue capaz de conocer a Yahvé haciendo camino con El —un camino que iba, en esencia, de la esclavitud (en todas sus formas) a la libertad $^{59}$ y que se manifestaba, necesariamente, en un estilo de vida, en consonancia con la alianza del Dios justo, misericordioso, a favor de los pobres-, así también la comunidad cristiana, según Mc, sólo encontrará y comprenderá al Jesús resucitado, "haciendo camino" con él"

Pero no se trata de un camino cualquiera, sino que es el camino que llevó a Jesús a la cruz (cfr. 8, 34ss). Este camino tiene, por tanto, unos rasgos muy concretos, que desconcertaron a los representantes oficiales del pueblo de Israel (iy no sólo a ellos!: cfr. infra), que se olvidaron de que no se pueden hacer imágenes de Dios. Pues es el Deus semper maior, el "Dios siempre más grande", que rompe los esquemas religiosos de los seres humanos, que no dejan a Dios ser Dios y manifestarse de modo soberano, en la paradoja de la cruz.

Este camino es un camino de fe, que no tiene otras garantías que las propias de la $\mathrm{fe}^{60}$. El evangelio quiere ser una iniciación y una guía para este camino de

58. Como nota muy bien $\mathrm{R}$. de Sivatte, "la única manera como se puede conocer a Dios es por la experiencia que el ser hombre tiene de El, en su historia, y que es testimoniada y confirmada por otros hombres y hechos. Es la experiencia de su actuación salvífica, liberadora. En consecuencia, cualquier otra imagen de Dios se convierte, en el Antiguo Testamento, en la imagen de un ídolo alienante y sacrificador de los hombres; deja de ser Yahvé, el Dios que ha sido descubierto en los actos liberadores" (Relació de coneixement entre Déu i l'home a l'Antic Testament. Lección inaugural del curso académico 1980-1981 de la Facultad de Teologia, Sant Cugat, 1980, p. 15).

59. “La meta, si es que Marcos hubiera utilizado alguna vez la palabra o pensamiento en estos términos, es Jesús. Pero como meta, Jesús no es una meta fija o estática. sino que está continuamente en movimiento, hacia la cruz y hacia la misión, y para Marcos, estas dos son inseparables" (E. Best, Following Jesús. Discipleship in the Gospel of Mark, Sheffield, 1981, p. 248).

60. La experiencia pascual es, esencialmente, una experiencia de fe. Ya santo Tomás decla que los discĺpulos vieron a Jesús resucitado con los ojos de la fe (oculara 
fe. En este itinerario que conduce al encuentro con el resucitado, mientras se espera la venida del Hijo del hombre en la parusía (cfr. 13,26), que está ya a las puertas (cfr. 13, 28-36) ${ }^{6}$, la comunidad, como los discípulos, tiene unos apoyos que le ayudan a orientarse: el Espíritu de Jesús, que los inspirará y los conducirá en las persecuciones inevitables ( $c f r .13,11$ ), la palabra y la promesa de Jesús, que no puede fallar (cfr. 14, 28 con 16,7) y toda la vida del crucificado, que les sirve de polo orientador, en el seguimiento de Jesús, que los llevará hacia la misión universal, que él les ha encomendado (cfr. 13,10) ${ }^{62}$.

Lo que acabo de decir queda aún más claro, si analizamos el significado de Mc $16,8 \mathrm{~b}$, un texto también redaccional ${ }^{63}$, que constituía el final absoluto del evangelio original de Mc.

Continuará.

fide viderunt): Summa Theologica III q. 55, a. 2 ad 1 ; cfr. q. 55, a. 1 ad 2 y 3; cfr. también W. Kasper, "Der Glaube an die Auferstehung Jesu vor dem Forum historischer Kritik", Theologische Quartalschrift 153 (1973) 239. Con razón, resalta Lohfink, Der Ablouf, 178: "Si la resurrección de Jesús es un acontecimiento escatológico en el sentido que hemos mostrado, entonces no es un milagro cualquiera, que prueba nuestra $\mathrm{fe}$, sino que entonces es el mismo punto central de nuestra fe, que sólo puede ser captado en la fe" (el subrayado es mío).

61. Al no narrarse las apariciones pascuales, la espera de la parusía adquiere más relieve en Mc que en los otros evangelios, pues, como observa Standaert, op. cit., p. 112: "Si Marcos no narra explícilamente las apariciones, sino que se conforma con hacer referencia a ellas $(16,7)$, es que él y su comunidad viven más en la espera del futuro, en la gran expectativa de la noche pascual: la venida del reino en la persona del Mesías (ver 9, 1 y 15, 43)".

62. Cfr. Gnilka, op. cit., Vol. II, pp. 222s.

63. Cfr. Gnilka, op. cit., Vol. II, p. 395 y los autores citados por él; cfr. también Schmitt, op. cit., pp. 533 y 558; Holfmann, op. cit., p. 498; Benito, op. cit., p. 283, el cual subraya el paralelismo del oudeni oudèn eipan del v. $8 \mathrm{~b}$ con el mêdeni mêdèn eípês, de Mc 1, 44 (una "orden de silencio"), y el de ephoboûnto (sin complemento) con el del tercer anuncio de la pasión (cfr. 10, 32). Benito, ibid., p. 288 critica, con razón, la conjetura de J. Luzárraga. "Retraducción semítica de ephobünto en Mc 16, 8", Biblica 50 (1969) 497-510, según la cual, detrás del verbo phobéomai, se encuentra la raiz semítica bhl, que sirve tanto para expresar "miedo" como "movimiento": L. parafrasea, entonces, el texto del v. 8b asl: "Las mujeres salieron presurosas del sepulcro y no se deluvieron a decir nada a nadie, pues iban a todo correr". Me he detenido en este análisis, porque es importante notar que, si el texto es redaccional, entonces, nos revela un interés particular del evangelista. 